\title{
Formate hydrogen lyase mediates stationary-phase deacidification and increases survival during sugar fermentation in acetoin-producing enterobacteria
}

\section{Bram Vivijs ${ }^{1}$, Leticia U. Haberbeck ${ }^{1,2}$, Victor Baiye Mfortaw Mbong ${ }^{2}$, Kristel Bernaerts ${ }^{3}$, Annemie H. Geeraerd ${ }^{2}$, Abram Aertsen ${ }^{1}$ and Chris W. Michiels ${ }^{1}{ }^{*}$}

\author{
' Laboratory of Food Microbiology and Leuven Food Science and Nutrition Research Centre, Department of Microbial and Molecular Systems, Faculty of \\ Bioscience Engineering, KU Leuven, Leuven, Belgium \\ ${ }^{2}$ Division of Mechatronics, Biostatistics and Sensors, Department of Biosystems, Faculty of Bioscience Engineering, KU Leuven, Leuven, Belgium \\ ${ }^{3}$ Chemical and Biochemical Process Technology and Control Section, Department of Chemical Engineering, Faculty of Engineering Science, KU Leuven, \\ Leuven, Belgium
}

\section{Edited by:}

Michael Gänzle, Alberta Veterinary

Research Institute, Canada

\section{Reviewed by:}

Carmen Wacher, Universidad Nacional Autónoma de México, Mexico

Michael Gänzle, Alberta Veterinary

Research Institute, Canada

\section{*Correspondence:}

Chris W. Michiels, Laboratory of Food

Microbiology and Leuven Food

Science and Nutrition Research

Centre, Department of Microbial and

Molecular Systems, Faculty of

Bioscience Engineering, KU Leuven,

Kasteelpark Arenberg 22,

3001 Leuven, Belgium

e-mail: chris.michiels@biw.

kuleuven.be
Two fermentation types exist in the Enterobacteriaceae family. Mixed-acid fermenters produce substantial amounts of lactate, formate, acetate, and succinate, resulting in lethal medium acidification. On the other hand, 2,3-butanediol fermenters switch to the production of the neutral compounds acetoin and 2,3-butanediol and even deacidify the environment after an initial acidification phase, thereby avoiding cell death. We equipped three mixed-acid fermenters (Salmonella Typhimurium, S. Enteritidis and Shigella flexneri) with the acetoin pathway from Serratia plymuthica to investigate the mechanisms of deacidification. Acetoin production caused attenuated acidification during exponential growth in all three bacteria, but stationary-phase deacidification was only observed in Escherichia coli and Salmonella, suggesting that it was not due to the consumption of protons accompanying acetoin production. To identify the mechanism, 34 transposon mutants of acetoin-producing E. coli that no longer deacidified the culture medium were isolated. The mutations mapped to 16 genes, all involved in formate metabolism. Formate is an end product of mixed-acid fermentation that can be converted to $\mathrm{H}_{2}$ and $\mathrm{CO}_{2}$ by the formate hydrogen lyase (FHL) complex, a reaction that consumes protons and thus can explain medium deacidification. When $h y c E$, encoding the large subunit of hydrogenase 3 that is part of the FHL complex, was deleted in acetoin-producing E. coli, deacidification capacity was lost. Metabolite analysis in E. coli showed that introduction of the acetoin pathway reduced lactate and acetate production, but increased glucose consumption and formate and ethanol production. Analysis of a hycE mutant in S. plymuthica confirmed that medium deacidification in this organism is also mediated by FHL. These findings improve our understanding of the physiology and function of fermentation pathways in Enterobacteriaceae.

Keywords: mixed-acid fermentation, 2,3-butanediol fermentation, acid stress, hydrogenase 3, formate hydrogen lyase

\section{INTRODUCTION}

Within the Enterobacteriaceae family, a distinction is made between mixed-acid (e.g., Escherichia, Salmonella, and Shigella) and 2,3-butanediol fermenters (e.g., Klebsiella, Serratia, and Enterobacter) based on their fermentation end products produced during sugar fermentation. Mixed-acid fermenters ferment sugars to ethanol and a range of organic acids, including lactate, succinate, acetate, and formate. Formate can be further converted to $\mathrm{H}_{2}$ and $\mathrm{CO}_{2}$ by the formate hydrogen lyase (FHL) complex (White, 2000). Mixed-acid fermentation generally leads to rapid and strong medium acidification and even cell death. On the other hand, 2,3-butanediol fermenters use the mixed-acids pathway only during the early growth phase, and switch in the late exponential phase to a different fermentation pathway, in which pyruvate is converted to the neutral end products acetoin or 2,3-butanediol, thereby preventing excessive acidification (Van Houdt et al., 2006; Xiao and Xu, 2007). Moreover, after the initial decline of medium $\mathrm{pH}, 2,3$-butanediol fermenters typically deacidify the medium toward more neutral values during stationary phase (Johansen et al., 1975; Yoon and Mekalanos, 2006; Van Houdt et al., 2007; Moons et al., 2011). This is in contrast to mixedacid fermenters or 2,3-butanediol fermenters with an inactivated 2,3-butanediol pathway, where a sustained $\mathrm{pH}$ decrease is usually observed during sugar fermentation (Yoon and Mekalanos, 2006; Moons et al., 2011). Thus, 2,3-butanediol fermentation is apparently associated with stationary-phase deacidification. Synthesis of 2,3-butanediol from pyruvate requires three steps. First, the conversion of two molecules of pyruvate to $\alpha$-acetolactate is catalyzed by the $\alpha$-acetolactate synthase ( $\alpha$-ALS). Next, $\alpha$-acetolactate is decarboxylated to acetoin by the $\alpha$-acetolactate decarboxylase 
$(\alpha$-ALD). In a last step, acetoin is reduced to 2,3-butanediol by the 2,3-butanediol dehydrogenase (BDH), which can also catalyze the reversed reaction. Each of these three reactions consumes an intracellular proton, and this potentially explains the observed stationary-phase deacidification. In Serratia plymuthica RVH1, a strain previously isolated from a food processing environment (Van Houdt etal., 2005), $\alpha$-ALS and $\alpha$-ALD are encoded by the $b u d B$ and $b u d A$ genes, respectively, which are located on the $b u d A B$ operon (Moons et al., 2011). We previously showed that transfer of the S. plymuthica RVH1 budAB operon conveys to Escherichia coli the capacity to produce acetoin, to prevent lethal medium acidification and to reverse acidification (Vivijs et al., 2014a). In the present study, we transferred the budAB operon to some additional mixed-acid fermenting enterobacteria, Salmonella Typhimurium, Salmonella Enteritidis, and Shigella flexneri, and show that these also acquire the capacity to produce acetoin. However, acetoin production was not associated with stationary-phase deacidification in S. flexneri. This observation is remarkable since Shigella and E. coli are considered as a single species based on DNA homology (Fukushima et al., 2002). Thus, our results suggested the involvement of a deacidification mechanism different from proton consumption during acetoin production. To identify this mechanism, we performed random transposon mutagenesis in budAB-containing E. coli searching for mutants that lost their stationary-phase deacidification capacity but still produced acetoin. This led us to identify the FHL complex as the primary deacidification mechanism in 2,3-butanediol-fermenting Enterobacteriaceae.

\section{MATERIALS AND METHODS}

BACTERIAL STRAINS, PLASMIDS, OLIGONUCLEOTIDES, AND GROWTH CONDITIONS

The bacterial strains and plasmids used in this study are listed in Table 1. All bacteria were cultured in lysogeny broth (LB; $10 \mathrm{~g} / \mathrm{l}$ tryptone, $5 \mathrm{~g} / \mathrm{l}$ yeast extract, $5 \mathrm{~g} / \mathrm{l} \mathrm{NaCl}$ ) or on $\mathrm{LB}$ agar ( $15 \mathrm{~g} / \mathrm{l}$ agar) at $37^{\circ} \mathrm{C}$ except Serratia plymuthica, which was grown at $30^{\circ} \mathrm{C}$. Media were supplemented with the following chemicals (Applichem, Darmstadt, Germany) when appropriate: $5 \mathrm{~g} / 1$

Table 1 | Strains and plasmids used in this study.

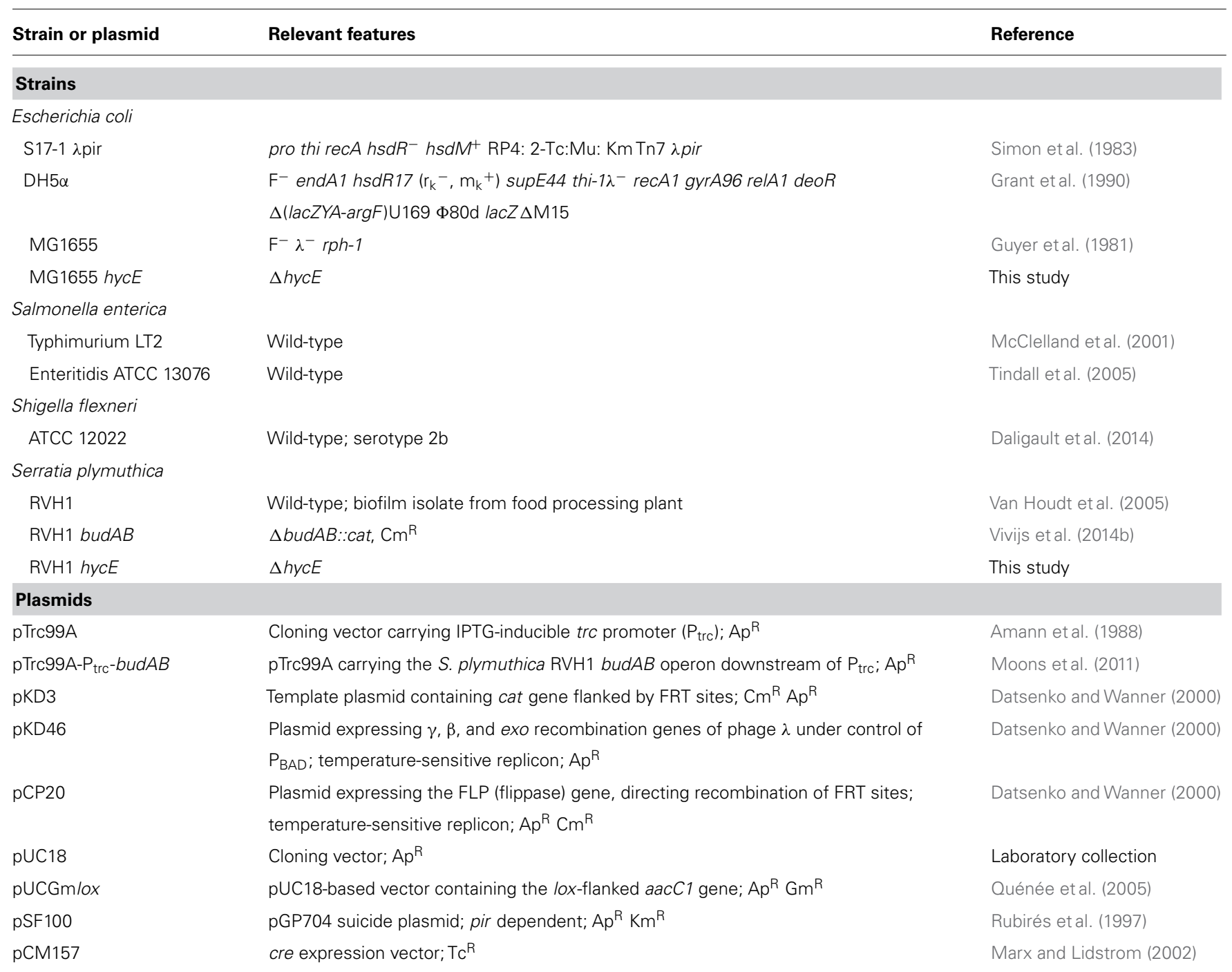


glucose; $100 \mu \mathrm{g} / \mathrm{ml}$ ampicillin (Ap); $200 \mu \mathrm{g} / \mathrm{ml}$ carbenicillin (Cb); $30 \mu \mathrm{g} / \mathrm{ml}$ chloramphenicol $(\mathrm{Cm}) ; 5 \mu \mathrm{g} / \mathrm{ml}$ gentamicin $(\mathrm{Gm}) ; 10$ $\mu \mathrm{g} / \mathrm{ml}$ tetracycline (Tc); $50 \mu \mathrm{g} / \mathrm{ml}$ kanamycin $(\mathrm{Km})$; and $1 \mathrm{mM}$ isopropyl- $\beta$-D-thiogalactopyranoside (IPTG). Plasmids $\mathrm{p} \operatorname{Trc} 99 \mathrm{~A}$ and $\mathrm{p} \operatorname{Trc} 99 \mathrm{~A}-\mathrm{P}_{\mathrm{trc}}-b u d A B$ were introduced into the mixed-acid fermenters by electroporation. All oligonucleotides used in this work are listed in Table 2, and were purchased from IDT (Haasrode, Belgium).

\section{SCREENING FOR MUTANTS THAT HAVE LOST STATIONARY-PHASE DEACIDIFICATION CAPACITY}

A random knockout library of E. coli MG1655 containing pTrc99A-P $\mathrm{Prc}-b u d A B$ was constructed using $\lambda$ NK1324, which carries a mini- $\mathrm{Tn} 10$ transposon with a $\mathrm{Cm}$ resistance gene, according to the protocol described by Kleckner et al. (1991). The mutants were subsequently grown in $300 \mu \mathrm{l} \mathrm{LB}$ medium with glucose, IPTG, Ap, and $\mathrm{Cm}$ in a 96-well plate. The plates were sealed with an oxygen impermeable cover foil and incubated without shaking at $37^{\circ} \mathrm{C}$. After $24 \mathrm{~h}$, medium acidification was analyzed by adding $5 \mu \mathrm{l}$ of a $0.06 \% \mathrm{w} / \mathrm{v}$ methyl red solution in $60 \% \mathrm{v} / \mathrm{v}$ ethanol to $200 \mu \mathrm{l}$ culture (MR test). For mutants that no longer deacidified the medium, the remaining $100 \mu \mathrm{l}$ culture was subjected to the Voges-Proskauer (VP) test by adding $30 \mu \mathrm{l}$ of $5 \%$ w/v $\alpha$-naphthol and $10 \mu \mathrm{l}$ of $40 \% \mathrm{w} / \mathrm{v} \mathrm{KOH}$ to $100 \mu \mathrm{l}$ of culture. To quantify acetoin production, the mixture was stirred vigorously after $1 \mathrm{~h}$ and the optical density at $550 \mathrm{~nm}\left(\mathrm{OD}_{550}\right)$ was measured. Acetoin concentrations were determined using a standard curve relating the $\mathrm{OD}_{550}$ with the acetoin concentration in LB medium. From mutants that did not deacidify culture medium and still produced acetoin, transposon insertion sites were determined using the method described by Kwon and Ricke (2000). Briefly, genomic DNA of the mutants was isolated, digested with NlaIII and ligated with a Y-shaped linker,

Table 2 | Oligonucleotides used in this study.

\begin{tabular}{ll}
\hline Primer & Sequence $\mathbf{( 5}^{\prime}$-3 $\left.^{\prime}\right)$ \\
\hline Linker 1 & TTTCTGCTCGAATTCAAGCTTCTAACGATGTAC \\
Linker 2 & TGGGACACATG \\
& ATCCACAT \\
Y linker primer & CTGCTCGAATTCAAGCTTCT \\
NK_Cm_DWN & CCTCCCAGAGCCTGATAA \\
EC_HycE_pKD3_1 & GCCGTGCCGGTTTTGATGACTTTTTTGATAAAGGT \\
& AAACATGGCGATTCCATGGGAATTAGCCATGGTCC \\
EC_HycE_pKD3_2 & TTTTTAGCGTTCGTCTCCTTGCTGGCGGCGTGATTA \\
& AAGAGAGTTTGAGCGTGTAGGCTGGAGCTGCTTC \\
SP_HycE_1(Xbal) & GCAGTCTAGAATCAGCGTCTGGTTCATTGG \\
SP_HycE_2(Xbal) & ACTCTCTAGATTATCTGTTCGCCGTGGTGC \\
SP_HycE_3(Xhol) & GCGACTCGAGCATGATGTTCCTACTTGTGAATTAGC \\
SP_HycE_4(Xhol) & GCACTCGAGCGGAAAAACGCACCGTTTTAA \\
LoxP_Gm_1(Xhol) & AACTCGAGCTTCAGCTGTACAATTGGTAC \\
LoxP_Gm_2(Xhol) & AACTCGAGACCGGTTAACACGCG
\end{tabular}

composed of oligonucleotides linker 1 and linker 2. Next, a PCR amplification was carried out using a transposon-specific primer (NK_Cm_DWN) and a primer specific to the Y-shaped linker (Y linker primer). The PCR product was subsequently sequenced using the transposon-specific primer and the insertion site was determined based on the known genome sequence of E. coli MG1655.

\section{CONSTRUCTION OF hycE MUTANTS IN E. coli AND S. plymuthica}

The deletion of $h y c E$ in E. coli MG1655 was achieved using the lambda red recombinase system described by Datsenko and Wanner (2000), followed by removal of the introduced antibiotic resistance cassette using the FRT/FLP recombination system. Briefly, 70-bp PCR primers were designed comprising a 50-bp $5^{\prime}$ part complementary to the region down- or upstream of $h y c E$ and a 20-bp $3^{\prime}$ part allowing amplification of the FRTflanked $\mathrm{Cm}$ resistance cassette present in the plasmid pKD3. The purified PCR product was electrotransformed into E. coli MG1655 containing the pKD46 plasmid providing the lambda red recombinase. The resistance cassette was subsequently removed by expression of the flippase recombination enzyme (FLP) of the FRT/FLP recombination system on the temperature-sensitive pCP20 plasmid.

To delete the hycE gene in S. plymuthica RVH1, a fragment encompassing $643 \mathrm{bp}$ upstream and $559 \mathrm{bp}$ downstream of the gene was PCR-amplified using primers SP_HycE_1(XbaI) and SP_HycE_2(XbaI), cut with XbaI, ligated into a XbaIdigested pUC18 vector and transformed into E. coli DH5 $\alpha$. The resulting plasmid pUC18- $h y c E$ was used as a template for PCR using the outward-oriented primers SP_HycE_3(XhoI) and SP_HycE_4(XhoI). In a separate reaction, the loxP flanked Gm resistance cassette from plasmid pUCGmlox was amplified using primers LoxP_Gm_1(XhoI) and LoxP_Gm_2(XhoI). Both PCR products were then cleaved with XhoI and ligated together, generating pUC18-hycE::aacC1, which was transformed in E. coli $\mathrm{DH} 5 \alpha$. The hycE::aacC1 insert from this plasmid was then amplified using primers SP_HycE_1(XbaI) and SP_HycE_2(XbaI), cut with XbaI, ligated into a XbaI-digested pSF100 vector and transformed into E. coli S17-1 $\lambda$ pir. After conjugation of the resulting plasmid pSF100-hycE::aacC1 into S. plymuthica RVH1 (which does not support replication of this suicide plasmid), transconjugants were selected on $\mathrm{LB}$ agar with $\mathrm{Gm}$ at $15^{\circ} \mathrm{C}$. This temperature allows good growth of S. plymuthica but prevents growth of E. coli S17-1 $\lambda$ pir. Loss of Km resistance (pSF100 marker) was assessed by replica plating on LB agar with $\mathrm{Km}$. The Gm resistance cassette was then spliced out using the cre recombinase on plasmid pCM157, which catalyzes site specific recombination between loxP sites. Restriction endonucleases and T4 DNA ligase were purchased from Thermo Scientific (St. Leon Rot, Germany) and used according to the supplier's instructions.

\section{CHARACTERIZATION OF FERMENTATIVE GROWTH AND FERMENTATION END PRODUCTS}

Strains were first grown overnight at the appropriate incubation temperature in $4 \mathrm{ml} \mathrm{LB}$. For strains containing pTrc99A or $\mathrm{p} \operatorname{Tr} c 99 \mathrm{~A}-\mathrm{P}_{\text {trc }}-b u d A B$, Ap was added to ensure plasmid 
maintenance. Since S. plymuthica RVH1 is somewhat Ap resistant, $\mathrm{Cb}$ was used instead of Ap. Next, the cultures were diluted 1:1000 in tubes containing $30 \mathrm{ml} \mathrm{LB}$ with glucose and, when appropriate, IPTG and Ap or Cb. Five $\mathrm{ml}$ of paraffin oil was layered on top of the cultures to create anaerobic conditions and the tubes were incubated at the appropriate incubation temperature for $48 \mathrm{~h}$. The cultures were sampled at regular time points to determine cell concentrations, medium $\mathrm{pH}$ and acetoin concentration, and for analysis of fermentation end products. Plate counts were determined by spot-plating $(5 \mu \mathrm{l})$ a decimal dilution series in potassium phosphate buffer $(10 \mathrm{mM} ; \mathrm{pH} 7.00)$ on LB agar. Gas production was evaluated qualitatively using Durham tubes. Fermentation end products were analyzed in $600 \mu \mathrm{l}$ culture supernatants stored at $-20^{\circ} \mathrm{C}$. Succinic, lactic, formic, and acetic acid, ethanol, and glucose were determined via high-performance liquid chromatography (HPLC; Agilent 1200 series) using an ion exclusion column (Aminex $\left.{ }^{\circledR} \mathrm{HPX}-87 \mathrm{H}\right)$ maintained at $55^{\circ} \mathrm{C}$, and with $5 \mathrm{mM} \mathrm{H}_{2} \mathrm{SO}_{4}$ as the mobile phase $(0.6 \mathrm{ml} / \mathrm{min})$. The system was equipped with a refractive index detector operating at $35^{\circ} \mathrm{C}$ and a diode array detector set at $210 \mathrm{~nm}$.

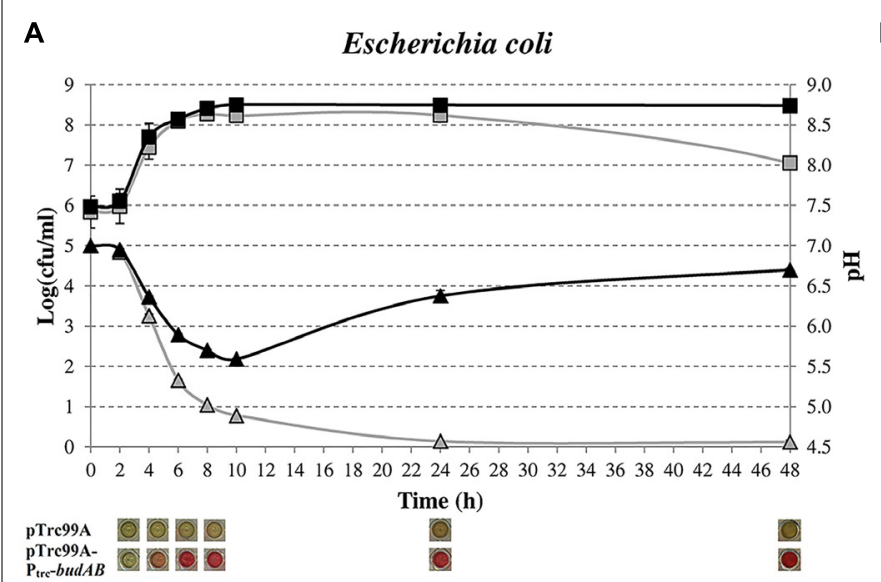

C

Salmonella Typhimurium

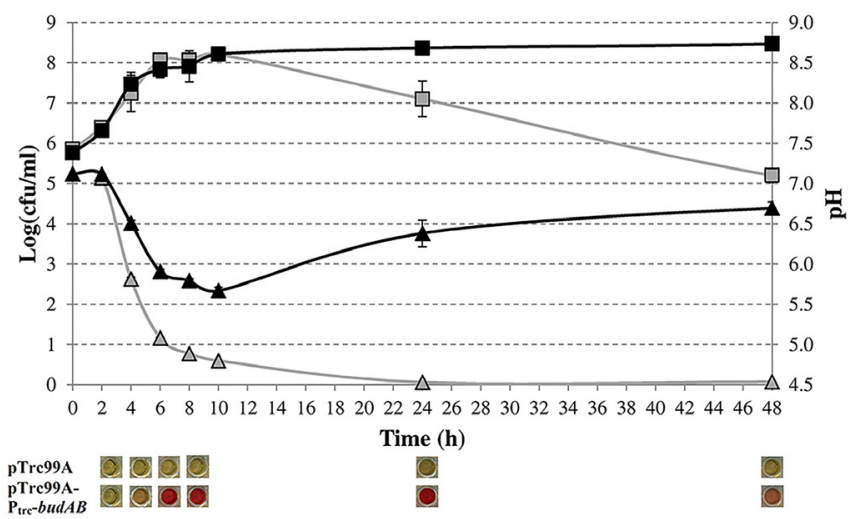

FIGURE 1 | Growth of Escherichia coli MG1655 (A), S. flexneri ATCC 12022 (B), S. Typhimurium LT2 (C) and S. Enteritidis ATCC 13076 (D) in LB medium containing $5 \mathrm{~g} / \mathrm{l}$ glucose, $1 \mathrm{mM}$ IPTG and $100 \mu \mathrm{g} / \mathrm{ml}$ ampicillin (Ap), in sealed microtiter plates incubated at $37^{\circ} \mathrm{C}$ for $\mathbf{4 8} \mathrm{h}$. Cell numbers

\section{STATISTICAL ANALYSIS}

All experiments were carried out in triplicate using independent cultures, and results are presented as the mean values \pm SD. Statistical significance between mean values were determined by Student's $t$-test analysis using the Microsoft Excel statistical package. Results were reported as significant when a $p$-value of $<0.05$ was obtained, based on a two-sided $t$-test with unequal variance.

\section{RESULTS AND DISCUSSION INTRODUCTION OF ACETOIN SYNTHESIS PATHWAY IN MIXED-ACID FERMENTERS}

Previously, we introduced the $b u d A B$ operon from S. plymuthica RVH1, encoding the $\alpha$-ALS and $\alpha$-ALD of the acetoin synthesis pathway, in E. coli MG1655 and observed that this attenuated lethal medium acidification during fermentative growth on glucose (Vivijs etal., 2014a). Here, we extended this experiment to $S$. Typhimurium, S. Enteritidis, and S. flexneri by introducing the pTrc $99 \mathrm{~A}-\mathrm{P}_{\text {trc }}-b u d A B$ plasmid into these organisms to see whether other mixed-acid fermenters would show a similar behavior. Figure 1 shows the growth curves and medium $\mathrm{pH}$ during fermentative growth in glucose-containing LB medium of these

B Shigella flexneri



D

Salmonella Enteritidis

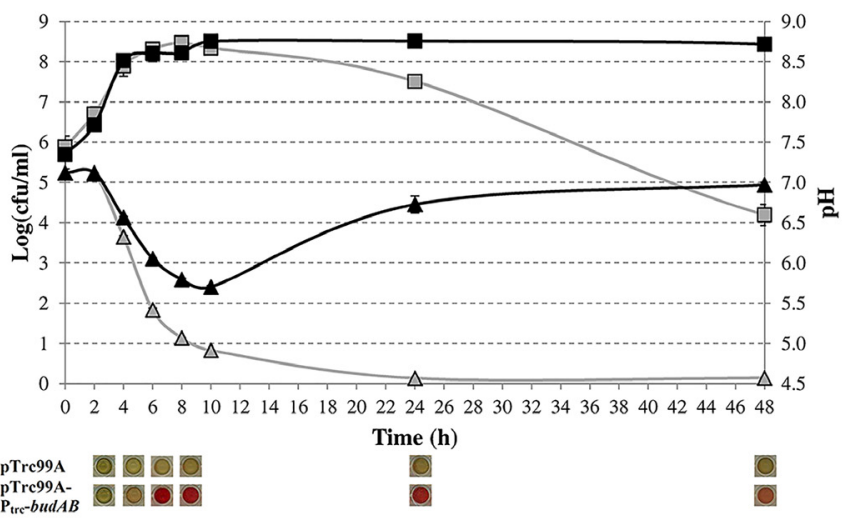

(squares) and medium $\mathrm{pH}$ (triangles) of strains harboring $\mathrm{p} \operatorname{Trc99A}$ (gray) or pTrc99A-P trc-budAB (black) are shown. Pictures below the figures show the results of the VP test, with a red color indicating the presence of acetoin.

Error bars represent SD. 
bacteria with and without the $b u d A B$ genes. As expected, E. coli, both Salmonella strains and S. flexneri without budAB strongly acidified the medium (to $\mathrm{pH} 4.50-4.70$ after $48 \mathrm{~h}$ ) and this resulted in cell death during the stationary phase. Introduction of the budAB genes did not change growth of the bacteria until stationary phase was reached, but it changed the $\mathrm{pH}$ profile of the E. coli and Salmonella cultures in two aspects. Firstly, the acidification during the growth phase was less strong, reaching a minimum $\mathrm{pH}$ of about 5.60. Secondly, the $\mathrm{pH}$ increased again during stationary phase, up to 6.60-7.00 after $48 \mathrm{~h}$. As a result, plate counts remained almost constant once they had reached their maximal stationary phase level (10-48 h).

Surprisingly, a different pattern was observed in S. flexneri. Introduction of the $b u d A B$ genes also attenuated medium acidification during the growth phase ( $\mathrm{pH} 5.60$ after $10 \mathrm{~h}$ ), but no deacidification occurred during stationary phase. As a result, this culture reached a final $\mathrm{pH}$ of 4.80 after $48 \mathrm{~h}$ and the plate counts decreased to a similar extent as those of the strain without budAB genes. The strain with the $b u d A B$ genes produced acetoin in similar amounts as the E. coli and Salmonella strains carrying these genes, so that poor expression of the acetoin pathway could be ruled out to explain the different behavior of S. flexneri. Therefore, proton consumption in the acetoin production pathway cannot fully explain the deacidification during stationary phase in E. coli and Salmonella, and it can be concluded that other deacidification mechanisms must be involved.

\section{SCREENING FOR LOSS OF DEACIDIFICATION CAPACITY IN E. coli CONTAINING A FUNCTIONAL ACETOIN PATHWAY}

In order to identify additional mechanisms involved in stationaryphase deacidification, we performed random transposon mutagenesis in E. coli MG1655 containing the pTrc99A- $\mathrm{P}_{\text {trc }}-b u d A B$ plasmid and searched for mutants that were unaffected in acetoin production (VP test), yet were no longer able to increase the $\mathrm{pH}$ of glucose-containing LB medium at $37^{\circ} \mathrm{C}$ after $24 \mathrm{~h}$ (MR test), thus having a $\mathrm{MR}+/ \mathrm{VP}+$ phenotype. Although in most Enterobacteriaceae a positive VP test is usually associated with a negative $\mathrm{MR}$ test (MR-/VP+, e.g., Enterobacter aerogenes) and vice versa (MR+/VP-, e.g., E. coli), there are also some species in this family (e.g., Enterobacter intermedius, Klebsiella planticola, or Serratia liquefaciens) reported to be positive for both tests $(\mathrm{MR}+/ \mathrm{VP}+$; Holt et al., 1994).

Out of 6.048 mutants screened, $34 \mathrm{MR}+/ \mathrm{VP}+$ mutants were identified and their phenotype was confirmed after transferring the mutation to a native MG1655 strain by P1-transduction, followed by transformation of pTrc $99 \mathrm{~A}-\mathrm{P}_{\mathrm{trc}}-b u d A B$. Identification of the transposon insertion sites of these 34 mutants led to 16 different genes (Table 3). Interestingly, all genes were related to the metabolism of formate, one of the acids formed by mixedacid fermentation. Formate is produced by the pyruvate formate lyase (PFL) enzyme, which catalyzes the CoA-dependent cleavage of pyruvate to formate and acetyl-CoA (Sawers and Böck, 1988). An overview of the fermentation routes present in E. coli containing pTrc99A- $\mathrm{P}_{\operatorname{trc}}-b u d A B$ is shown in Figure 2. The formate that is produced and secreted can also be reimported in the cell through the FocA channel and become disproportionated to $\mathrm{CO}_{2}$ and $\mathrm{H}_{2}$ by the membrane-associated FHL complex
Table 3 | List of genes knocked out in transposon insertion mutants of E. coli MG1655 containing $\mathrm{p}$ Trc99A-P $\mathrm{Ptc}-$-budAB that had lost the stationary-phase deacidification capacity but still produced acetoin (MR+/VP+).

\begin{tabular}{|c|c|}
\hline Gene & Description \\
\hline$f d h D$ & $\begin{array}{l}\text { Redox enzyme maturation protein (REMP) for FdnG/FdoG; } \\
\text { required as a sulfurtransferase for FDH activity }\end{array}$ \\
\hline$f d h F$ & $\mathrm{FDH}-\mathrm{H}$ \\
\hline$f h / A$ & FHL system activator \\
\hline focA & Formate channel \\
\hline hycB & FHL complex iron-sulfur protein \\
\hline hycD & FHL complex inner membrane protein \\
\hline hycE & Hydrogenase 3 large subunit \\
\hline hycl & Maturation endoprotease for hydrogenase 3 large subunit $\mathrm{HycE}$ \\
\hline hypE & $\begin{array}{l}\text { Maturation protein required for the assembly of the } \mathrm{CN} \text { ligand } \\
\text { of the NiFe metal center of hydrogenase } 1,2 \text {, and } 3 .\end{array}$ \\
\hline $\bmod C$ & ATP binding subunit of the molybdate $A B C$ transporter \\
\hline moeA & Molybdopterin molybdenumtransferase \\
\hline moeB & Molybdopterin-synthase adenylyltransferase \\
\hline $\operatorname{mog}$ & $\begin{array}{l}\text { Molybdochelatase incorporating molybdenum into } \\
\text { molybdopterin }\end{array}$ \\
\hline$p f \mid B$ & Pyruvate formate lyase \\
\hline selA & Selenocysteine synthase \\
\hline seld & Selenophosphate synthase \\
\hline
\end{tabular}

(Sawers, 2005; Lü et al., 2012; Beyer et al., 2013). This complex consists of the formate dehydrogenase $\mathrm{H}$ (FDH-H), a selenoprotein carrying a molybdenum cofactor, and hydrogenase 3 , a nickel-containing protein complex (Bagramyan and Trchounian, 2003). FDH-H catalyzes the oxidation of formate $\left(\mathrm{HCOO}^{-}\right)$, generating $\mathrm{CO}_{2}$ and $\mathrm{H}^{+}$. The electrons from this reaction are transferred via several subunits of the FHL complex to hydrogenase 3, where they combine with two cytoplasmic protons to form dihydrogen. This pathway is thus a net consumer of protons and is used by E. coli to counteract acidification (Leonhartsberger etal., 2002). All gene products found in our screening could be linked to this particular pathway: FdhF (FDH-H), HycB, $\mathrm{HycD}$, and $\mathrm{HycE}$ are part of the FHL complex (Bagramyan and Trchounian, 2003); HycI and HypE are both involved in maturation of the large subunit of hydrogenase 3 (Forzi and Sawers, 2007); SelA and SelD take part in the biosynthesis of selenocysteine, and mutants lacking these gene products fail to synthesize FDH-H (Leinfelder et al., 1988; Driscoll and Copeland, 2003); ModC is the ATP binding subunit of the molybdate ABC transporter and MoeA, MoeB, and Mog are other ancillary enzymes that participate in the biosynthesis of the molybdenum cofactor (Sawers, 1994; Grunden and Shanmugam, 1997; Leimkühler et al., 2001; Nichols and Rajagopalan, 2002); FdhD is an accessory protein functioning as a sulfurtransferase between IscS and FdhF and is required for FDH activity (Thomé et al., 2012); FocA and PflB are coexpressed from a single operon and form a bidirectional formate channel and the PFL enzyme, respectively 


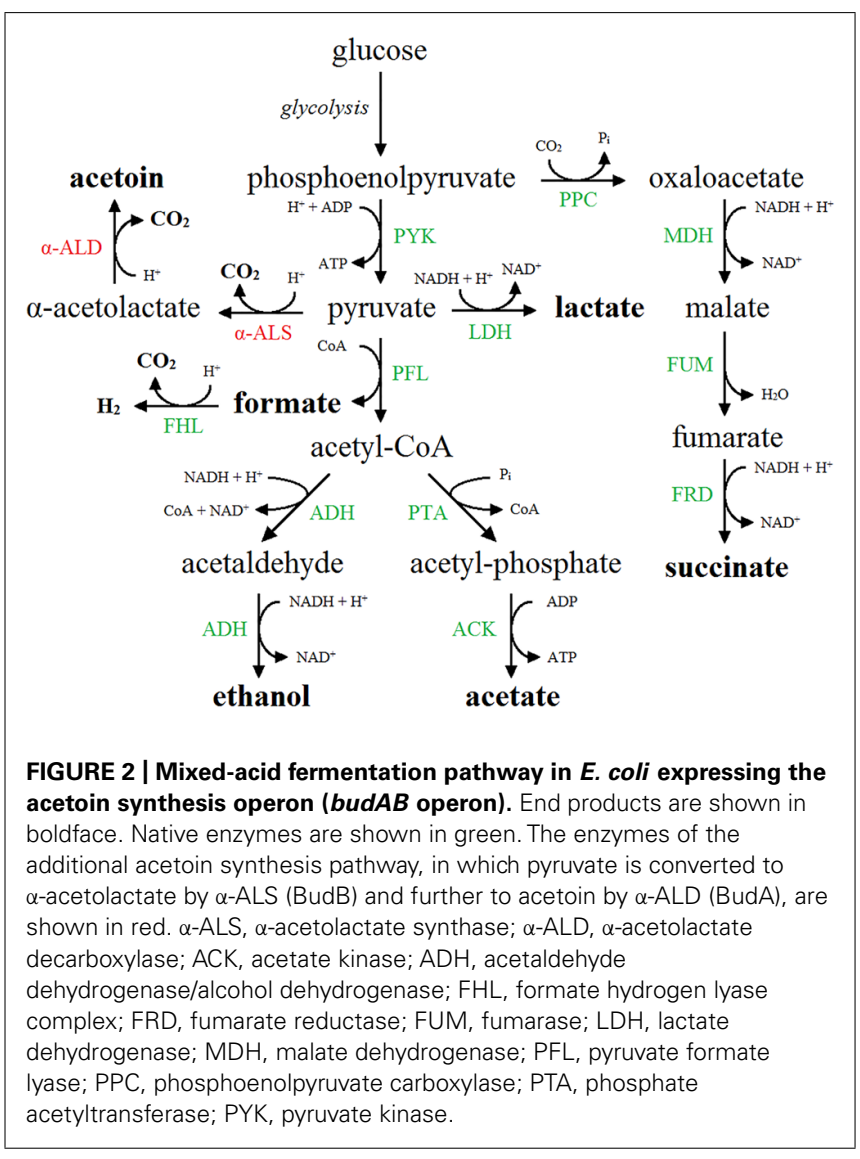

(Lü et al., 2012); FhlA, finally, is a transcriptional activator of the FHL system (Leonhartsberger et al., 2002). In conclusion, the mutant screening approach provides a strong indication that the disproportionation of formate is responsible for the stationaryphase deacidification capacity in E. coli containing the budAB genes.

In addition to hydrogenase $3, E$. coli also possesses three other hydrogenases catalyzing the reversible reaction $2 \mathrm{H}^{+}+2 \mathrm{e}^{-} \leftrightarrow \mathrm{H}_{2}$. Hydrogenase 1 and 2 are $\mathrm{H}_{2}$-oxidizing enzymes which are maximally induced at low and alkaline $\mathrm{pH}$, respectively (Trchounian et al., 2012). Hydrogenase 4 is not well characterized and its subunits have not been isolated and studied yet, but it may be part of a second FHL complex that may produce $\mathrm{H}_{2}$ at neutral and slightly alkaline pH (Self et al., 2004; Trchounian and Sawers, 2014). The contribution of hydrogenase 3 to acid resistance has been demonstrated previously since anaerobic cultures of E. coli W3110 $\Delta h y c E$ showed a 20 -fold loss in survival of an extreme acid stress $(2 \mathrm{~h}$ at $\mathrm{pH}$ 2.0) when compared to the wild-type strain (Noguchi et al., 2010). This finding suggested that the FHL complex supports survival of extreme acid challenge by counteracting intracellular acidification. Our results now show that the complex can also accomplish an increase of the environmental $\mathrm{pH}$ during growth under moderate acid stress, thereby preventing stationary phase cell death during fermentative growth.

The observation that acetoin-producing S. flexneri showed reduced acidification in the exponential growth phase, but did not deacidify the medium during the stationary phase (Figure 1), can also be linked to formate conversion. Although S. flexneri closely resembles E. coli at the genetic level, Shigella species (with the exception of a few strains) do not produce gas during carbohydrate fermentation (Brenner et al., 1982; Germani and Sansonetti, 2006). We confirmed that the S. flexneri strain used in this study did not produce gas from glucose and the absence of this mechanism may thus explain our observation. The reason why Shigella species do not produce gas in the presence of glucose is unclear. The genes encoding the FDH-H and the hydrogenase 3 are present in the Shigella genome, but apparently no functional FHL complex is formed.

\section{EFFECT OF HYDROGENASE 3 INACTIVATION ON FERMENTATIVE GROWTH OF ACETOIN-PRODUCING $E$. coli}

To characterize in more detail the role of formate disproportionation on the capacity of $E$. coli (with or without $b u d A B$ genes) to attenuate medium acidification during fermentative growth, we constructed a clean deletion of the $h y c E$ gene. Since this gene encodes the large subunit of the hydrogenase 3 that contains the active site for proton reduction to dihydrogen (Trchounian et al., 2012), its deletion completely blocks the conversion of formate to $\mathrm{CO}_{2}$ and $\mathrm{H}_{2}$. Next, budAB-less and budAB-containing wildtype and $\triangle h y c E$ strains of E. coli MG1655 were grown for $48 \mathrm{~h}$ in glucose-containing LB medium sealed from the air with a paraffin oil layer and with a Durham tube to observe gas production. Plate counts, medium $\mathrm{pH}$, gas production and acetoin concentrations were determined at regular time points (Figure 3; Table 4). Knockout of $h y c E$ did not have any effect on the $\mathrm{pH}$ profile during fermentative growth of budAB-less E. coli over the entire $48 \mathrm{~h}$ growth period. In the $b u d A B$-containing strains, the effect of $h y c E$ deletion depended on the growth phase. During the exponential phase (first $6 \mathrm{~h}$ ), hycE deletion had no effect on the acidification, but it can be seen that the acidification was slightly less compared to the two budAB-less strains, in line with the earlier observations shown in Figure 1. However, from the onset of stationary phase, the $\mathrm{pH}$ profile of both acetoin-producing strains diverged strongly. While acidification by the budAB-containing wild-type strain slowed down and reversed into deacidification after $12 \mathrm{~h}$ of growth (as already shown in Figure 1), acidification by the $b u d A B$-containing $\triangle h y c E$ mutant was sustained until $24 \mathrm{~h}$, after which the $\mathrm{pH}$ remained stable at a low value $(\mathrm{pH}=4.72)$. Since both strains produced similar amounts of acetoin, and acetoin production stopped after $10 \mathrm{~h}$ (Table 4), it can be concluded that the stationary-phase deacidification by the budAB-containing wild-type E. coli MG1655 is not a direct consequence of proton consumption during acetoin production.

More likely, deacidification is triggered by proton consumption in the reaction carried out by the FHL complex since deletion of $h y c E$ resulted in loss of deacidification. This explanation is also supported by the observed gas production. Since $\mathrm{CO}_{2}$ is very soluble in water, gas accumulation in a Durham tube can be mainly ascribed to $\mathrm{H}_{2}$ production, and is thus indicative of the action of the FHL complex (White, 2000). Both strains with an intact FHL complex produced more or less the same amount of gas at $12 \mathrm{~h}$, filling approximately half of the Durham tube with gas (Figure 3). However, no additional gas production was seen in case of wild-type E. coli after $12 \mathrm{~h}$, while the Durham 

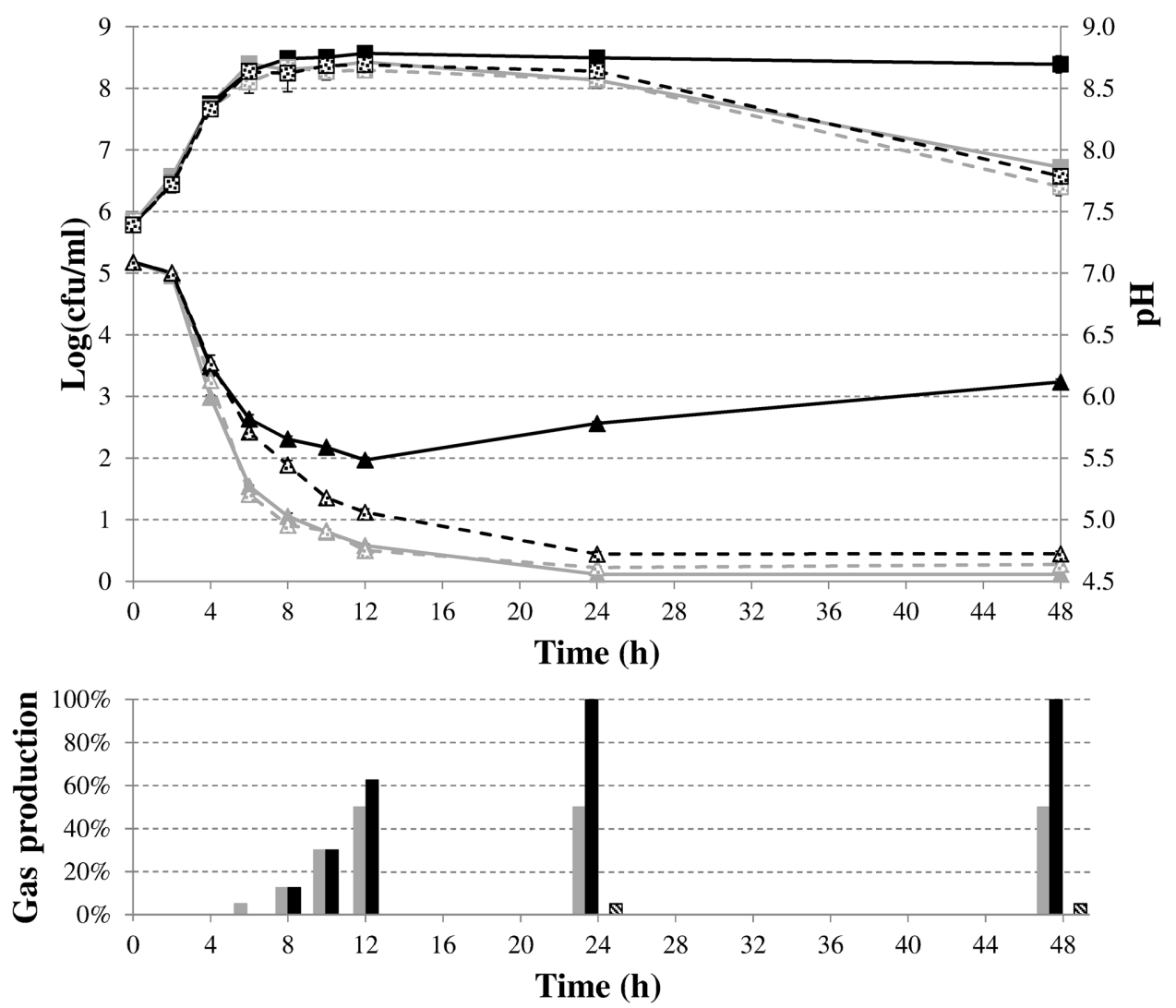

FIGURE 3 | Cell numbers (squares) and medium pH (triangles) during fermentative growth of $E$. coli MG1655 wild-type (solid lines) or $\Delta h y c E$ (dashed lines) containing pTrc99A (gray) or pTrc99A-P trc-budAB (black) in LB medium with $5 \mathrm{~g} / \mathrm{l}$ glucose, $1 \mathrm{mM}$ IPTG and $100 \mu \mathrm{g} / \mathrm{ml}$ Ap at $37^{\circ} \mathrm{C}$ for $\mathbf{4 8} \mathbf{h}$. Error bars represent SD. Gas production (expressed as \% of the volume of the Durham tube) is shown at the bottom.
Table 4 | Acetoin production (in $\mathrm{mM}$ ) by E. coli MG1655 containing pTrc99A-P $\mathrm{P}_{\text {trc }}-$ budAB or E. coli MG1655 $\triangle$ hycE containing pTrc99A-P trc $^{-}$-budAB during fermentative growth in LB with $5 \mathrm{~g} / \mathrm{l}$ glucose, $1 \mathrm{mM}$ IPTG, and $100 \mu \mathrm{g} / \mathrm{ml}$ ampicillin (Ap) for $48 \mathrm{~h}$.

\begin{tabular}{lll}
\hline Time (h) & $\begin{array}{l}\text { E. coli MG1655 } \\
\text { pTrc99A-P }_{\text {trc }} \text {-budAB }\end{array}$ & $\begin{array}{l}\text { E. coli MG1655 } \Delta \text { hycE } \\
\text { pTrc99A-P trc-budAB }\end{array}$ \\
\hline 4 & $0.7 \pm 0.2$ & $0.5 \pm 0.2$ \\
6 & $5.3 \pm 0.7$ & $5.0 \pm 0.4$ \\
8 & $9.8 \pm 0.9$ & $7.1 \pm 1.3$ \\
10 & $21.8 \pm 0.8$ & $18.4 \pm 0.5$ \\
12 & $19.4 \pm 1.2$ & $12.5 \pm 1.1$ \\
24 & $18.7 \pm 0.7$ & $12.3 \pm 0.5$ \\
48 & $20.5 \pm 2.3$ & $11.1 \pm 2.3$ \\
\hline
\end{tabular}

tubes in case of acetoin-producing E. coli were completely filled with gas after $24 \mathrm{~h}$, and additional gas bubbles were formed in the medium after $48 \mathrm{~h}$. On the other hand, the $\Delta h y c E$ mutant did not produce any gas, while only a small amount of gas was observed in the budAB-containing $\triangle h y c E$ mutant, which might be the result of $\mathrm{CO}_{2}$ production during acetoin formation (Figure 3).
The evolution of plate counts during stationary phase in this experiment was generally in line with the observed $\mathrm{pH}$ changes, with cell death taking place in the strongly acidified cultures. In particular, lethal acidification could not be prevented by acetoin fermentation in a budAB-containing $\triangle h y c E$ mutant since plate counts of this strain significantly decreased after the stationary phase, as was also the case for the two budAB-less strains performing a mixed-acid fermentation. Cell death can be explained by the combination of the low $\mathrm{pH}$ environment and the toxic accumulation of organic acids.

\section{ANALYSIS OF METABOLITES PRODUCED DURING FERMENTATIVE GROWTH OF E. coli}

To provide more direct evidence for the involvement of formate disproportionation in the deacidification capacity of budABcontaining E. coli, glucose consumption and the production of metabolites were determined by HPLC during fermentative growth in LB with glucose (Figure 4). Succinate concentrations (Figure 4E) remained low for all strains during the course of the experiment. On the other hand, the $b u d A B$ genes caused a marked shift in the production of two of the major acids of the mixed-acid fermentation pathway, especially in the late exponential and stationary growth phase, with no more acetate and much less lactate being produced (Figures 4C,D, respectively). With 

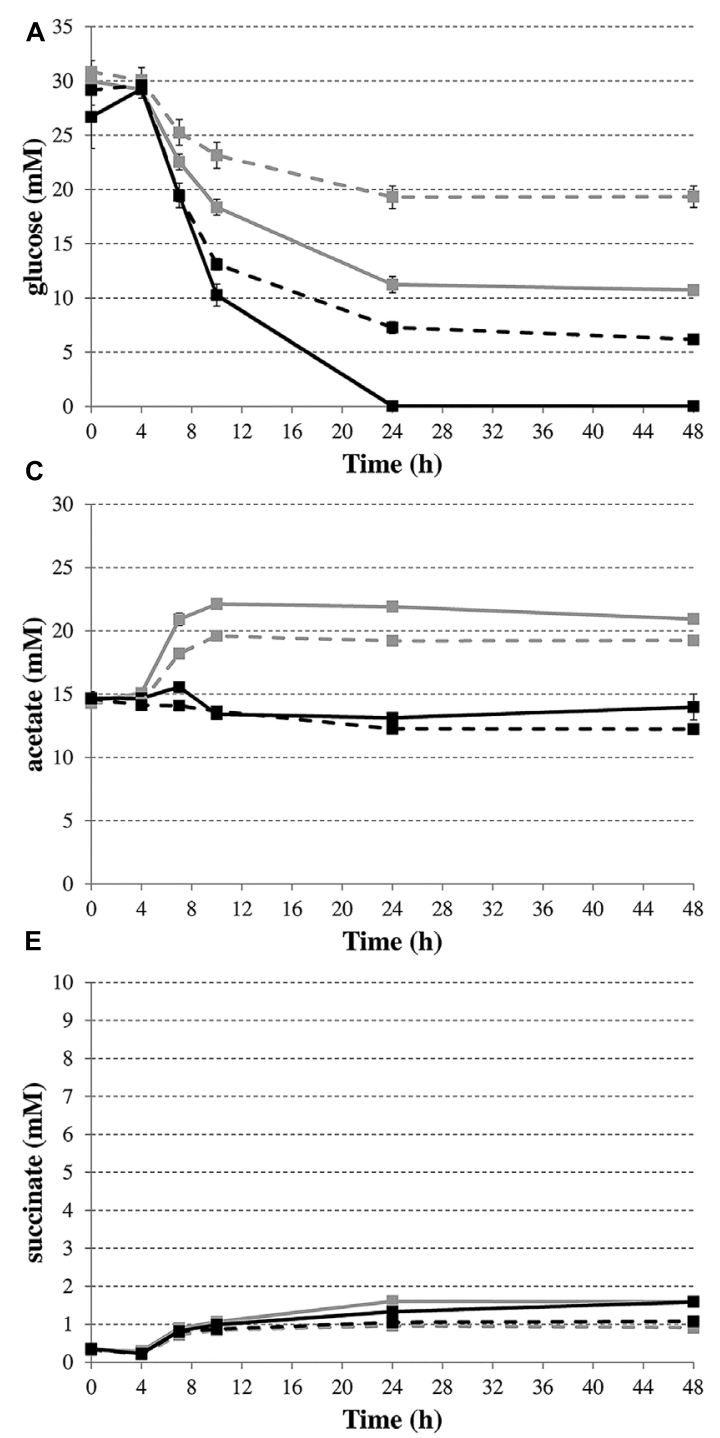

FIGURE 4 | Time profiles of glucose consumption (A) and production of the metabolites ethanol (B), acetate (C), lactate (D), succinate (E), and formate $(F)$ during fermentative growth of $E$. coli MG1655 wild-type
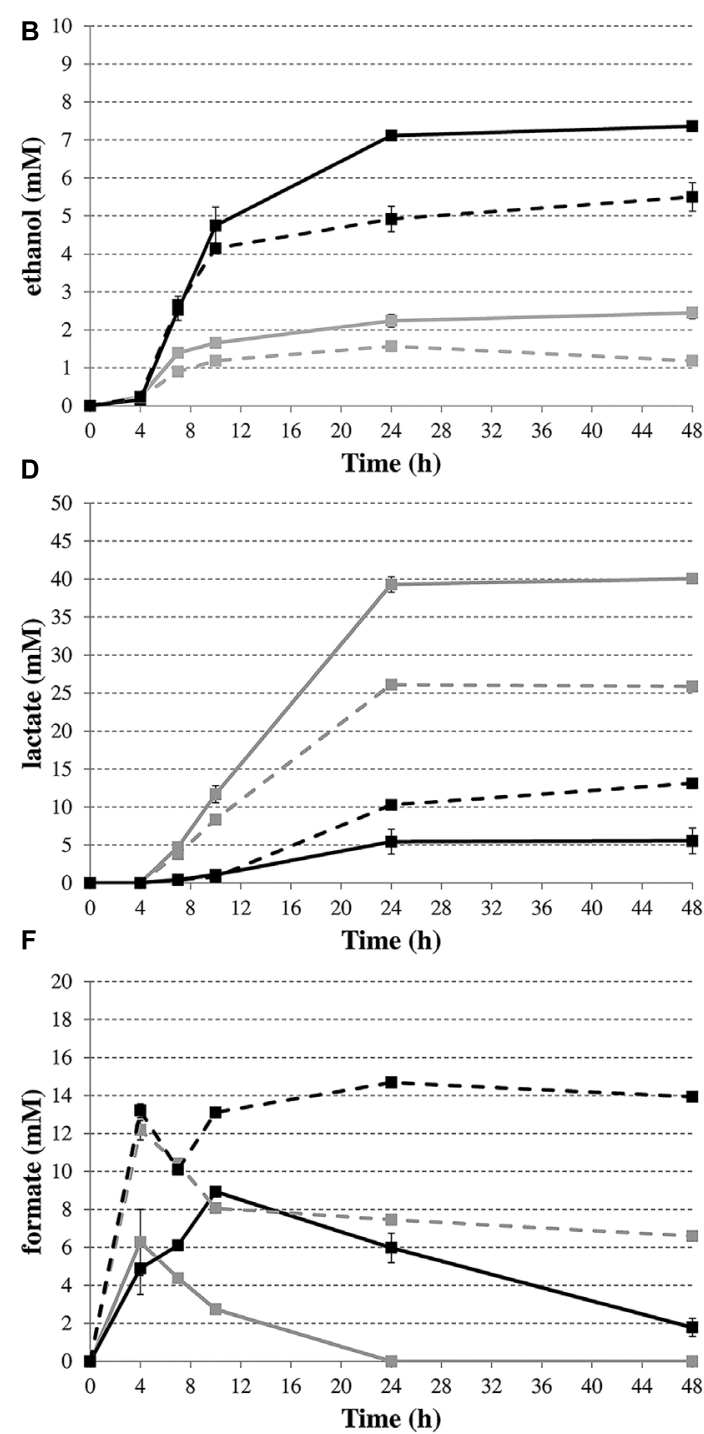

(solid lines) or $\Delta$ hycE (dashed lines) containing pTrc99A (gray) or pTrc99A-P trc -budAB (black) in LB medium with $5 \mathrm{~g} / \mathrm{l}$ glucose, $1 \mathrm{mM}$ IPTG and $100 \mu \mathrm{g} / \mathrm{ml} \mathrm{Ap}$ at $37^{\circ} \mathrm{C}$ for $\mathbf{4 8} \mathrm{h}$. Error bars represent SD. regard to formate (Figure 4F), the highest formate accumulation was seen in the $\triangle h y c E$ mutants, probably because these have lost their major route to convert formate to $\mathrm{H}_{2}$ and $\mathrm{CO}_{2}$. During the stationary growth phase (up to $48 \mathrm{~h}$ ), the formate concentrations remained almost constant in the $h y c E^{-}$strains, but strongly decreased in the $h y c E^{+}$strains, indicating the reuptake and conversion of formate to $\mathrm{CO}_{2}$ and $\mathrm{H}_{2}$. Interestingly, a close look at the formate accumulation curves of the $\Delta h y c E$ mutants reveals a transient decline in the late exponential growth phase (onset at $4 \mathrm{~h}$ of growth). Also in the $h y c E^{+}$background a decline (budAB-less strain) or a diminished accumulation (budAB-containing strain) of formate was observed in this phase. A possible explanation for this is the activity of the FDH-N, which also catalyzes the oxidation of formate to $\mathrm{CO}_{2}$ (Sawers, 1994). However, FDH-N transfers the electrons to nitrate (via a nitrate reductase) instead of protons and has a much higher affinity for formate than the FDH-H (Leonhartsberger et al., 2002), which could explain why it is active in an earlier growth stage. The activity of FDH-N is limited, however, because LB medium contains only a small amount of nitrate. The disproportionation of formate (Figure $4 \mathrm{~F}$ ) by the $h y c E^{+}$strains lasted longer when the budAB genes were present $(48 \mathrm{~h})$ than when they were absent $(24 \mathrm{~h})$, probably because a higher amount of formate was produced. This was also reflected by an increased gas production in the presence of the $b u d A B$ genes during this phase, as reported above (Figure 3). Finally, ethanol was produced in higher quantities by the budAB-containing strains (Figure 4B).

As a final experiment to demonstrate that formate conversion causes medium deacidification during stationary phase, 5 or $10 \mathrm{mM}$ formate from a $1 \mathrm{M}$ solution ( $\mathrm{pH}$ 5.50) was added to the 
Table 5 | Effect of exogenous formate addition on $\mathrm{pH}$ of fermentation medium.

\begin{tabular}{llll}
\hline $\begin{array}{l}\text { Concentration of } \\
\text { formate added at } \mathbf{1 0 ~} \mathbf{h}\end{array}$ & $\mathbf{1 0} \mathbf{h}$ & $\mathbf{2 4} \mathbf{h}$ & $\mathbf{4 8 ~ h}$ \\
\hline $0 \mathrm{mM}$ & $5.64 \pm 0.03^{\mathrm{a}}$ & $5.81 \pm 0.04^{\mathrm{a}}$ & $6.14 \pm 0.02^{\mathrm{a}}$ \\
$5 \mathrm{mM}$ & $5.66 \pm 0.05^{\mathrm{a}}$ & $5.96 \pm 0.04^{\mathrm{b}}$ & $6.35 \pm 0.04^{\mathrm{b}}$ \\
$10 \mathrm{mM}$ & $5.63 \pm 0.08^{\mathrm{a}}$ & $6.05 \pm 0.04^{\mathrm{c}}$ & $6.48 \pm 0.05^{\mathrm{c}}$ \\
\hline
\end{tabular}

E. coli MG1655 harboring pTrc99A-P $P_{\text {trc }}$-budAB was grown in LB medium with $5 \mathrm{~g} / \mathrm{g} / \mathrm{ucose}, 1 \mathrm{mM} / \mathrm{PTG}$, and $100 \mu \mathrm{g} / \mathrm{ml} \mathrm{Ap}$. Formate was added at $10 \mathrm{~h}$ and $\mathrm{pH}$ was measured at 10, 24, and $48 \mathrm{~h} .{ }^{\mathrm{a}-\mathrm{C}} \mathrm{pH}$ values with different superscripts in the same column are significantly different $(p<0.05)$.



FIGURE 5 | Cell numbers (squares) and medium $\mathrm{pH}$ (triangles) during fermentative growth of $S$. plymuthica RVH1 wild-type (black solid lines), budAB::cat (gray solid lines), budAB::cat containing pTrc99A-P trc-budAB (dashed line), or $\Delta$ hycE (dotted line) in LB medium with $5 \mathrm{~g} / \mathrm{l}$ glucose at $30^{\circ} \mathbf{C}$ for $\mathbf{4 8} \mathrm{h}$. For the strain containing pTrc99A-P trc $_{\text {-budAB, }} 1 \mathrm{mM}$ IPTG and $200 \mu \mathrm{g} / \mathrm{ml}$ carbenicillin (Cb) were added to the medium. Error bars represent SD.

medium after $10 \mathrm{~h}$ of fermentative growth of budAB-containing E. coli MG1655 and the $\mathrm{pH}$ was subsequently measured after 10, 24 , and $48 \mathrm{~h}$. As expected, the addition of formate in the medium resulted in a significantly stronger $\mathrm{pH}$ increase during stationary phase (Table 5).

Taken together, the metabolite profiles lead us to propose the following model to explain the effect of introduction of the budAB genes in E. coli (see Figure 2). The introduction of these genes diverts part of the pyruvate generated from glycolysis to acetoin production. At the same time, possibly because of a reduced cellular pyruvate pool, the balance between the mixed-acid fermentation routes is shifted, with lactate production being almost shut down. Nevertheless, since the budAB-containing strain produced higher amounts of formate (see previous paragraph), it maintains a higher flux of pyruvate to acetyl-CoA, as also indicated by the higher glucose consumption. This can be explained by the reduced acid production and consequently the reduced metabolic inhibition. The fate of acetyl-CoA is also different in the $b u d A B$-containing strain. This is necessarily so, because the reduced production of lactic acid creates an excess of $\mathrm{NADH}$ that must be reoxidized by another route to maintain the cellular redox balance. As can be seen in Figure 2, this is only possible by increasing ethanol production at the expense of acetate production. This is indeed what happens, since the budAB-containing strain no longer produces acetate and has increased ethanol production. Since acetate production is coupled to the generation of an extra ATP, introduction of the acetoin pathway reduces the ATP yield per mole of glucose fermented. However, this does not result in reduced growth rate (Figures 1 and 3 ), because it is compensated by a higher glucose turnover. Thus, although the total biomass production (maximal cell density reached in early stationary phase) is approximately the same for all the strains, the budAB-containing strains require much more glucose to achieve this (Figure 4A).

\section{ROLE OF HYDROGENASE 3 IN FERMENTATIVE GROWTH OF S. plymuthica RVH1}

Finally, we investigated whether the FHL complex also attenuates acid formation and drives deacidification during fermentative growth of a natural 2,3-butanediol fermenter, using $S$. plymuthica RVH1 as a model. To this end, we constructed a $\Delta h y c E$ mutant in this strain. The evolution of medium $\mathrm{pH}$ for S. plymuthica RVH1 wild-type shows three phases (Figure 5). There was a decrease during the first $8 \mathrm{~h}$, followed by a rapid increase between 8 and $10 \mathrm{~h}$, and then a slower increase until $48 \mathrm{~h}$. The initial $\mathrm{pH}$ increase is probably due to the switch to 2,3-butanediol production in the late exponential phase since it was lost upon knockout of the 2,3-butanediol pathway ( $b u d A B:: c a t)$ but not by knockout of hydrogenase $3(\Delta h y c E)$. In contrast, the deacidification during stationary phase required both an active 2,3-butanediol pathway and an active hydrogenase 3 . Genetic complementation of the $b u d A B$ mutant restored its $\mathrm{pH}$ profile to that of the wild-type strain. However, since this complemented strain produces acetoin under the control of the plasmid $\mathrm{P}_{\text {trc }}$ promoter right from the start of the experiment, its acidification is more attenuated than in the wildtype strain. Cell numbers declined after $48 \mathrm{~h}$ in the mutant strains that had lost or reduced deacidification capacity and, as a result, there was a clear correlation between cell numbers and medium $\mathrm{pH}$ at the end of the experiment.

Previously, the $\mathrm{pH}$ profile during glucose fermentation in the 2,3-butanediol fermenter Enterobacter aerogenes was divided into three phases (Johansen et al., 1975). The first phase was characterized by a rapid drop to about $\mathrm{pH} 5.8$, in the second phase the $\mathrm{pH}$ remained almost constant at $\mathrm{pH} 5.6$ and in the third phase the $\mathrm{pH}$ increased again to about 6.5. However, during the last phase, the total amount of acetoin and 2,3-butanediol remained constant and 2,3-butanediol was reoxidized to acetoin, indicating that the 2,3-butanediol pathway is not involved in this deacidification (Johansen et al., 1975). Our results demonstrate that -at least in $S$. plymuthica- the FHL complex is responsible for stationary-phase deacidification since the final $\mathrm{pH}$ was about $1.3 \mathrm{pH}$ units lower in a S. plymuthica RVH1 $\Delta h y c E$ mutant compared to the wild-type.

\section{ACKNOWLEDGMENTS}

This work was supported by a doctoral fellowship to BV from the Agency for Innovation by Science and Technology (IWT), by a research grant from the Brazilian program Science without Borders (process number 5511/10-0), by research grants from the 
Research Foundation - Flanders (FWO; G.A061.11), and from the KU Leuven Research Fund (METH/07/03). Kenneth Simoens is acknowledged for the HPLC metabolite analyses.

\section{REFERENCES}

Amann, E., Ochs, B., and Abel, K. (1988). Tightly regulated tac promoter vectors useful for the expression of unfused and fused proteins in Escherichia coli. Gene 69, 301-315. doi: 10.1016/0378-1119(88)90440-4

Bagramyan, K., and Trchounian, A. (2003). Structural and functional features of formate hydrogen lyase, an enzyme of mixed-acid fermentation from Escherichia coli. Biochemistry (Mosc.) 68, 1159-1170. doi: 10.1023/B:BIRY.0000009129.18 714.a4

Beyer, L., Doberenz, C., Falke, D., Hunger, D., Suppmann, B., and Sawers, R. G. (2013). Coordination of FocA and pyruvate formate-lyase synthesis in Escherichia coli demonstrates preferential translocation of formate over other mixed-acid fermentation products. J. Bacteriol. 195, 1428-1435. doi: 10.1128/JB.02166-12

Brenner, D. J., Steigerwalt, A. G., Wathen, H. G., Gross, R. J., and Rowe, B. (1982). Confirmation of aerogenic strains of Shigella boydii 13 and further study of Shigella serotypes by DNA relatedness. J. Clin. Microbiol. 16, 432-436.

Daligault, H. E., Davenport, K. W., Minogue, T. D., Bishop-Lilly, K. A., Broomall, S. M., Bruce, D. C., et al. (2014). Genome assembly of Shigella flexneri ATCC 12022, a quality control reference strain. Genome Announc. 2:e01052-14. doi: 10.1128/genomeA.01052-14

Datsenko, K. A., and Wanner, B. L. (2000). One-step inactivation of chromosomal genes in Escherichia coli K-12 using PCR products. Proc. Natl. Acad. Sci. U.S.A. 97, 6640-6645. doi: 10.1073/pnas.120163297

Driscoll, D. M., and Copeland, P. R. (2003). Mechanism and regulation of selenoprotein synthesis. Annu. Rev. Nutr. 23, 17-40. doi: 10.1146/annurev.nutr.23.011702.073318

Forzi, L., and Sawers, R. G. (2007). Maturation of [NiFe]-hydrogenases in Escherichia coli. Biometals 20, 565-578. doi: 10.1007/s10534-006-9048-5

Fukushima, M., Kakinuma, K., and Kawaguchi, R. (2002). Phylogenetic analysis of Salmonella, Shigella, and Escherichia coli strains on the basis of the gyrB gene sequence. J. Clin. Microbiol. 40, 2779-2785. doi: 10.1128/JCM.40.8.27792785.2002

Germani, Y., and Sansonetti, P. J. (2006). "The genus Shigella," in The Prokaryotes: A Handbook on the Biology of Bacteria, eds M. Dworkin, S. Falkow, E. Rosenberg, K. H. Schleifer, and E. Stackebrandt (New York, NY: Springer), 99-122. doi: 10.1007/0-387-30746-X_6

Grant, S. G. N., Jessee, J., Bloom, F. R., and Hanahan, D. (1990). Differential plasmid rescue from transgenic mouse DNAs into Escherichia coli methylation-restriction mutants. Proc. Natl. Acad. Sci. U.S.A. 87, 4645-4649. doi: $10.1073 /$ pnas. 87.12 .4645

Grunden, A. M., and Shanmugam, K. T. (1997). Molybdate transport and regulation in bacteria. Arch. Microbiol. 168, 345-354. doi: 10.1007/s002030050508

Guyer, M. S., Reed, R. R., Steitz, J. A., and Low, K. B. (1981). Identification of a sex-factor-affinity site in E. coli as $\gamma \delta$. Cold Spring Harb. Symp. Quant. Biol. 45, 135-140. doi: 10.1101/SQB.1981.045.01.022

Holt, J. G., Krieg, N. R., Sneath, P. H. A., Staley, J. T., and Williams, S. T. (1994). Bergey's Manual of Determinative Bacteriology. Baltimore: Williams \& Wilkins.

Johansen, L., Bryn, K., and Stormer, F. C. (1975). Physiological and biochemical role of the butanediol pathway in Aerobacter (Enterobacter) aerogenes. J. Bacteriol. $123,1124-1130$.

Kleckner, N., Bender, J., and Gottesman, S. (1991). Uses of transposons with emphasis on Tn10. Methods Enzymol. 204, 139-180. doi: 10.1016/00766879(91)04009-D

Kwon, Y. M., and Ricke, S. C. (2000). Efficient amplification of multiple transposon-flanking sequences. J. Microbiol. Methods 41, 195-199. doi: 10.1016/S0167-7012(00)00159-7

Leimkühler, S., Wuebbens, M. M., and Rajagopalan, K. V. (2001). Characterization of Escherichia coli MoeB and its involvement in the activation of molybdopterin synthase for the biosynthesis of the molybdenum cofactor. J. Biol. Chem. 276, 34695-34701. doi: 10.1074/jbc.M102787200

Leinfelder, W., Forchhammer, K., Zinoni, F., Sawers, G., Mandrand-Berthelot, M. A., and Böck, A. (1988). Escherichia coli genes whose products are involved in selenium metabolism. J. Bacteriol. 170, 540-546. doi: 10.1002/jtra.1033

Leonhartsberger, S., Korsa, I., and Böck, A. (2002). The molecular biology of formate metabolism in enterobacteria. J. Mol. Microbiol. Biotechnol. 4, 269-276.
Lü, W., Du, J., Schwarzer, N. J., Gerbig-Smentek, E., Einsle, O., and Andrade, S. L. A. (2012). The formate channel FocA exports the products of mixedacid fermentation. Proc. Natl. Acad. Sci. U.S.A. 109, 13254-13259. doi: 10.1073/pnas. 1204201109

Marx, C. J., and Lidstrom, M. E. (2002). Broad-host-range cre-lox system for antibiotic marker recycling in Gram-negative bacteria. BioTechniques 33, 1062-1067.

McClelland, M., Sanderson, K. E., Spieth, J., Clifton, S. W., Latreille, P., Courtney, L., et al. (2001). Complete genome sequence of Salmonella enterica serovar Typhimurium LT2. Nature 413, 852-856. doi: 10.1038/35101614

Moons, P., Van Houdt, R., Vivijs, B., Michiels, C. W., and Aertsen, A. (2011). Integrated regulation of acetoin fermentation by quorum sensing and $\mathrm{pH}$ in Serratia plymuthica RVH1. Appl. Environ. Microbiol. 77, 3422-3427. doi: 10.1128/AEM.02763-10

Nichols, J., and Rajagopalan, K. V. (2002). Escherichia coli MoeA and MogA function in metal incorporation step of molybdenum cofactor biosynthesis. J. Biol. Chem. 277, 24995-25000. doi: 10.1074/jbc.M203238200

Noguchi, K., Riggins, D. P., Eldahan, K. C., Kitko, R. D., and Slonczewski, J. L. (2010). Hydrogenase-3 contributes to anaerobic acid resistance of Escherichia coli. PLoS ONE 5:e101321. doi: 10.1371/journal.pone.0010132

Quénée, L., Lamotte, D., and Polack, B. (2005). Combined sacB-based negative selection and cre-lox antibiotic marker recycling for efficient gene deletion in Pseudomonas aeruginosa. BioTechniques 38, 63-67. doi: 10.2144/0538 $1 \mathrm{ST} 01$

Rubirés, X., Saigi, F., Piqué, N., Climent, N., Merino, S., Albertí, S., et al. (1997). A gene (wbbL) from Serratia marcescens $\mathrm{N} 28 \mathrm{~b}(\mathrm{O} 4)$ complements the $\mathrm{rfb}-50$ mutation of Escherichia coli K-12 derivatives. J. Bacteriol. 179, 7581-7586.

Sawers, G. (1994). The hydrogenases and formate dehydrogenases of Escherichia coli. Antonie Van Leeuwenhoek 66, 57-88. doi: 10.1007/BF008 71633

Sawers, G., and Böck, A. (1988). Anaerobic regulation of pyruvate formate-lyase from Escherichia coli K-12. J. Bacteriol. 170, 5330-5336.

Sawers, R. G. (2005). Formate and its role in hydrogen production in Escherichia coli. Biochem. Soc. Trans. 33, 42-46. doi: 10.1042/BST0330042

Self, W. T., Hasona, A., and Shanmugam, K. T. (2004). Expression and regulation of a silent operon, hyf, coding for hydrogenase 4 isoenzyme in Escherichia coli. J. Bacteriol. 186, 580-587. doi: 10.1128/JB.186.2.580-587.2004

Simon, R., Priefer, U., and Pühler, A. (1983). A broad host range mobilization system for in vivo genetic engineering: transposon mutagenesis in gram negative bacteria. Nat. Biotechnol. 1, 784-791. doi: 10.1038/nbt1183-784

Thomé, R., Gust, A., Toci, R., Mendel, R., Bittner, F., Magalon, A., et al. (2012). A sulfurtransferase is essential for activity of formate dehydrogenases in Escherichia coli. J. Biol. Chem. 287, 4671-4678. doi: 10.1074/jbc.M111.3 27122

Tindall, B. J., Grimont, P. A. D., Garrity, G. M., and Euzéby, J. P. (2005). Nomenclature and taxonomy of the genus Salmonella. Int. J. Syst. Evol. Microbiol. 55, 521-524. doi: 10.1099/ijs.0.63580-0

Trchounian, A., and Sawers, R. G. (2014). Novel insights into the bioenergetics of mixed-acid fermentation: can hydrogen and proton cycles combine to help maintain a proton motive force? IUBMB Life 66, 1-7. doi: 10.1002/iub.1236

Trchounian, K., Poladyan, A., Vassilian, A., and Trchounian, A. (2012). Multiple and reversible hydrogenases for hydrogen production by Escherichia coli: dependence on fermentation substrate, $\mathrm{pH}$ and the F0F1-ATPase. Crit. Rev. Biochem. Mol. Biol. 47, 236-249. doi: 10.3109/10409238.2012.655375

Van Houdt, R., Aertsen, A., and Michiels, C. W. (2007). Quorum-sensingdependent switch to butanediol fermentation prevents lethal medium acidification in Aeromonas hydrophila AH-1N. Res. Microbiol. 158, 379-385. doi: 10.1016/j.resmic.2006.11.015

Van Houdt, R., Moons, P., Buj, M. H., and Michiels, C. W. (2006). N-acyl-Lhomoserine lactone quorum sensing controls butanediol fermentation in Serratia plymuthica RVH1 and Serratia marcescens MG1. J. Bacteriol. 188, 4570-4572. doi: 10.1128/JB.00144-06

Van Houdt, R., Moons, P., Jansen, A., Vanoirbeek, K., and Michiels, C. W. (2005). Genotypic and phenotypic characterization of a biofilm-forming Serratia plymuthica isolate from a raw vegetable processing line. FEMS Microbiol. Lett. 246, 265-272. doi: 10.1016/j.femsle.2005.04.016

Vivijs, B., Moons, P., Aertsen, A., and Michiels, C. W. (2014a). Acetoin synthesis acquisition favors Escherichia coli growth at low pH. Appl. Environ. Microbiol. 80, 6054-6061. doi: 10.1128/AEM.01711-14 
Vivijs, B., Moons, P., Geeraerd, A. H., Aertsen, A., and Michiels, C. W. (2014b). 2,3-butanediol fermentation promotes growth of Serratia plymuthica at low $\mathrm{pH}$ but not survival of extreme acid challenge. Int. J. Food Microbiol. 175, 36-44. doi: 10.1016/j.ijfoodmicro.2014.01.017

White, D. (2000). The Physiology and Biochemistry of Prokaryotes. New York: Oxford University Press.

Xiao, Z., and Xu, P. (2007). Acetoin metabolism in bacteria. Crit. Rev. Microbiol. 33, 127-140. doi: 10.1080/10408410701364604

Yoon, S. S., and Mekalanos, J. J. (2006). 2,3-butanediol synthesis and the emergence of the Vibrio cholerae El Tor biotype. Infect. Immun. 74, 6547-6556. doi: 10.1128/IAI.00695-06

Conflict of Interest Statement: The authors declare that the research was conducted in the absence of any commercial or financial relationships that could be construed as a potential conflict of interest.
Received: 07 January 2015; paper pending published: 03 February 2015; accepted: 09 February 2015; published online: 25 February 2015.

Citation: Vivijs B, Haberbeck LU, Baiye Mfortaw Mbong V, Bernaerts K, Geeraerd AH, Aertsen A and Michiels CW (2015) Formate hydrogen lyase mediates stationary-phase deacidification and increases survival during sugar fermentation in acetoin-producing enterobacteria. Front. Microbiol. 6:150. doi: 10.3389/fmicb.2015.00150

This article was submitted to Food Microbiology, a section of the journal Frontiers in Microbiology.

Copyright (C) 2015 Vivijs, Haberbeck, Baiye Mfortaw Mbong, Bernaerts, Geeraerd, Aertsen and Michiels. This is an open-access article distributed under the terms of the Creative Commons Attribution License (CC BY). The use, distribution or reproduction in other forums is permitted, provided the original author(s) or licensor are credited and that the original publication in this journal is cited, in accordance with accepted academic practice. No use, distribution or reproduction is permitted which does not comply with these terms. 